\title{
A ANÁLISE ARQUEOLÓGICA DO DISCURSO EM MICHEL FOUCAULT: POR UMA LINGUÍSTICA DO ENUNCIADO
}

\author{
Sérgio Gomes de Miranda ${ }^{1}$ \\ Universidade Federal de Goiás (UFG) \\ (D) https://orcid.org/0000-0002-9568-485X
}

\begin{abstract}
RESUMO:
Os estudos da linguagem no século $\mathrm{XX}$ e agora no atual século são marcados pela hegemonia de três correntes de pesquisa: o Estruturalismo; o Inatismo e o Interacionismo. No Estruturalismo, o usuário da língua é submetido a um código soberano, contra o qual ele não tem escolha a não ser cumprir as normas do uso correto. Desviar do padrão significa erro. No Inatismo, prevalece o logicismo. Na mente do usuário reside tudo de que ele precisa para ser bem sucedido em sua linguagem. Se o usuário pensa corretamente, também correta será sua expressão linguística. Se o uso não condiz com a lógica de base é sinal de que o usuário não pensa corretamente. No Interacionismo, a linguagem é fruto da interação entre usuários ideologicamente e contextualmente delimitados. Os usos da língua são compartilhados de acordo com o conhecimento do usuário do quadro semântico e pragmático que reside em cada contexto. Na contra hegemonia dessas correntes, este texto rechaça essas três correntes e constrói a sua crítica a partir das ideias de Michel Foucault. Nesse sentido, vai sendo delineado o rumo conceitual dado pelo filósofo francês, uma nova proposta, denominada aqui de linguística do enunciado, sob a forma de uma arqueologia da linguagem, para dar conta dos discursos que dão sentido aos acontecimentos. Ainda, este texto relaciona essa arqueologia a um novo modelo de ensino da língua na escola, dando a essa prática escolar um sentido diferente do que tem imperado em diversas escolas desse país.
\end{abstract}

Palavras-Chave: Linguagem; Linguística do Enunciado; Arqueologia; Pesquisa; Ensino.

1. Doutorando pela Universidade Federal de Goiás (UFG), Goiás - Brasil. E-mail: <serginhosong@hotmail.com> 


\title{
THE ANALYSIS ARCHAEOLOGICAL OF THE SPEECH IN MICHEL FOUCAULT: FOR A LINGUISTICS OF THE STATEMENT
}

\begin{abstract}
:
Studies of language in the twentieth century and now in the present century are marked by the hegemony of three research currents: Structuralism; Innatism and Interactionism. In Structuralism, the language user is subjected to a sovereign code, against which he has no choice but to comply with the correct use standards. Deviate from the mean error. In Innatism prevails logicism. In the mind of the user resides everything he needs to be successful in their language. If the user think correctly, will also correct their linguistic expression. If the use is not consistent with the basic logic is a sign that you do not think properly. In Interactionism, the language is the result of interaction between users and ideologically defined contextually. The language uses are shared according to the user's knowledge of the semantic and pragmatic framework that resides in each context. In hegemony against these currents, this text rejects these three currents and builds its criticism from Michel Foucault's ideas. In this sense, is being outlined the conceptual direction given by the French philosopher, a new proposal, called here the linguistics of the statement, in the form of an archeology of language, to account for the speeches that give meaning to events. Still, this text relates this archeology to a new language teaching model in school, giving this school practice a different sense of what is commanded in various schools of the country.
\end{abstract}

KEYWORDS: Language; Linguistics of the Statement; Archaeology; Research; Teaching.

\section{Introdução}

O campo da pesquisa em linguagem tem em seu "DNA" a complexidade como caráter indispensável. Porém, essa complexidade tende a se alargar ainda mais quando a pesquisa procura entender práticas sociais tais como a sala de aula. São muitas e quase sempre divergentes as linhas filosóficas, teóricas e metodológicas que intentam desvelar a "verdade" para seus estudos. Como é fácil notar, os teóricos tendem a se apegar quase que espiritualmente às suas correntes, o que os tornam irredutíveis à compreensão de outras visões e noções que não sejam identificadas às suas formas de pensar. Esses "templos" teóricos, em sua defesa de fé, caem na mesma tentação: uma resposta definitiva e final para o seu problema de pesquisa. Com isso, acabam por limitar seu objeto aos recortes homogêneos, estabilizados, estanques, atômicos, centrados em campos e corpus 
delimitados, nos quais as respostas, se não são óbvias, são esperadas, para justificar os supostos potenciais de cientificidade que afirmam deter.

Sob a forma de apresentar uma perspectiva de estudo diferente e mais propícia à essência da linguagem, este texto tenta responder à seguinte pergunta: por que uma linguística do enunciado? Para tanto, ele se divide em duas partes: a primeira delas tece uma breve exposição da temática e da crítica referente a três grandes linhas de atuação no campo da pesquisa em linguagem. São elas: a linguística do sistema saussuriano; a linguística inatista chomskiana; e a linguística interacionista bakhitiniana. A segunda parte se dedica em trazer uma reflexão, também breve, mas um pouco mais profunda, acerca do pensamento de Michel Foucault a respeito das formas de pensar e de fazer a pesquisa por essas três linhas da linguística, bem como apresenta um outro rumo para os estudos da linguagem, substituindo a supremacia da forma, ou a dominância da lógica, ou a determinação ideológica contextual, pela análise e pela descrição arqueológica; isto é, pelo estudo do arquivo que se constitui através de uma historicidade dos acontecimentos enunciativos, por meio dos discursos que povoam a existência da língua e nossa existência. Este texto é breve demais para tratar de um tema tão abrangente. Contudo, quem se sentir instigado pela abordagem foucaultiana do problema aqui situado, poderá enxergar com mais abrangência sua filosofia se procurar fazer a leitura dos textos referenciados neste trabalho, principalmente "A Arqueologia do Saber", texto base para este estudo. Agora, sem mais demora, passa-se à tessitura do texto.

\section{A crítica à linguística do século XX: 0 Estruturalismo; 0 Inatismo; 0 Interacionismo}

não é o sistema de sua língua, nem, de uma maneira geral, as regras formais de sua construção; [...] A questão que coloco é aquela, não dos códigos, mas dos acontecimentos: a lei da existência dos enunciados, o que os torna possíveis - eles e algum outro em seu lugar; as condições de sua emergência singular, sua correlação com outros acontecimentos anteriores ou simultâneos, discursivos ou não. [...] sem me referir à consciência, obscura ou explícita, dos sujeitos falantes; sem relacionar os fatos de discurso à vontade - talvez involuntária de seus autores; sem invocar essa intenção de dizer que é sempre com excesso de riqueza em relação ao que diz; [...] nem uma formalização nem uma exegese. Mas uma arqueologia: quer dizer, como seu nome indica de maneira bastante evidente, a descrição do arquivo. (FOUCAULT, 2010, p. 09)

O Estruturalismo saussuriano é uma das correntes teóricas mais férteis no campo dos estudos linguísticos. Isso principalmente pelo longo tempo em que, no Brasil, essa corrente deteve a hegemonia nesse campo. 
Todavia, apesar de sua importância, não é difícil encontrar pesquisadores com pesadas críticas à linguística do sistema saussuriano. $\mathrm{O}$ teor da crítica à teoria de Saussure, ou às leituras que fazem dessa teoria, se acentua principalmente na eleição de seu objeto: um sistema supremo, soberano, superior ao falante/escritor usuário, que nada pode fazer frente a essa supremacia do sistema a não ser se render às regras, às normas, ao que lhe está posto a priori. Também, no que tange à pesquisa linguística, essa crítica se firma na postura positivista, objetiva que assume o pesquisador frente ao seu objeto. Sua atitude é descritiva e quantitativa, preocupada com os dados como fins em si mesmos.

É um fato marcante que todo esse quadro de exatificação e positivação da linguagem tornou-se princípio para a o ensino da língua nas práticas escolares, na medida em que os estudantes se submetem a uma ditadura da aprendizagem: um conjunto de termos e de nomenclaturas a serem aprendidos; elementos de uma língua que estão aprisionados às cartilhas escolares, aos livros e materiais didáticos, criacionistas da língua da escola, uma espécie de língua estrangeira aprisionada aos muros da escola, em detrimento da língua que esses estudantes conheciam antes de passar pelos seus portões. Crítico desse modelo, Marcuschi (2008) postula que "a língua não é um código autônomo, estruturado como um sistema abstrato e homogêneo, preexistente e exterior ao falante", mas que é determinada pelas condições de produção discursiva, "com base em textos produzidos em situações interativas, uma atividade social, histórica e cognitiva" (MARCUSCHI, 2008, P. 64). O mesmo autor acrescenta ainda que "a aula de língua materna é um tipo de ação que transcende o aspecto meramente interno ao sistema da língua" e reforça que a vida cultural humana é envolta pela linguagem e "todos os textos situam-se nessas vivências [...] um convite claro para o ensino situado em contextos reais da vida cotidiana" (MARCUSCHI, 2008, p. 173).

Os enganos na escolha do aparato teórico-metodológico têm, em larga escala, contribuído para um insucesso escolar que pode, inclusive, se perpetuar posteriormente à escola, por impregnarem nos aprendizes uma concepção errônea de qual é a verdadeira face da língua, bem como por gerarem nos mesmos um completo descaso pela leitura e pela escrita. Essa é a visão que Geraldi (2002) encampa e tece a crítica de que

[o] aluno, costumado, desde as primeiras ocupações sérias da vida, a salmodiar, na escola, enunciados que não percebe, a repetir passivamente juízos alheios, a apreciar, numa linguagem que não entende, assuntos estranhos a sua observação pessoal; educado, em suma, na prática incessante de copiar, conservar e combinar palavras, com absoluto desprezo de seu sentido, inteira ignorância da sua origem, total indiferença aos seus fundamentos reais, o cidadão encarna em si uma segunda natureza, assinalada por hábitos de impostura, de cegueira, de superficialidade. (GERALDI, 2002, p. 120)

A análise arqueológica do discurso em Michel Foucault: por uma linguística do enunciado - Sérgio Gomes de Miranda 
Como uma voz que soa forte na entoação dessa crítica ao sistema de Saussure, Bakhtin (2010) se posta contrariamente à posição dos representantes da linguística do sistema, os quais entendem a língua como um fator externo à consciência do indivíduo. Para esse autor, afirmar "que a língua, como sistema de normas imutáveis e incontestáveis, possui uma existência objetiva é cometer um grave erro" (BAKHTIN, 2010, p. 94) e acrescenta que "[o] sistema linguístico tal como é construído pelo objetivismo abstrato não é diretamente acessível à consciência do sujeito falante, definido por sua prática viva de comunicação social" (BAKHTIN, 2010, p. 99). De acordo com Bakhtin (2010), isso se dá pelo fato de a linguística ser filha da filologia, que tem na base de sua abordagem a língua como norma, bem como "procedimentos práticos e teóricos elaborados para o estudo das línguas mortas, que se conservaram em documentos escritos" (BAKHTIN, 2010, p.100. Grifos do autor).

Para não deixar dúvidas quanto à posição tomada por ele frente à linguística do sistema, Bakhtin (2010) rechaça definitivamente a visão estrutural da língua e elege a ideologia como a detentora do significado e dos sentidos dessa língua ao salientar que "não são palavras o que pronunciamos ou escutamos, mas verdades ou mentiras, coisas boas ou más, importantes ou triviais, agradáveis ou desagradáveis, etc. A palavra está sempre carregada de um conteúdo ou de um sentido ideológico ou vivencial" (BAKHTIN, 2010, p. 98 e 99. Grifos do autor). Esse autor elenca ainda o que ele considera como categorias do sistema; quais sejam: o estável prevalece sobre o mutável; o abstrato sobre o concreto; o sistemático sobre o histórico; as formas dos elementos sobre as do conjunto; o elemento isolado sobre a dinâmica da fala; a univocidade sobre a polissemia; a "linguagem como produto acabado, que se transmite de geração a geração"; ausência do "processo gerativo interno da língua" (BAKHTIN, 2010, p. 106. Grifos do autor). Todas essas categorias corroboram para uma noção de língua que se encontra estancada nos dicionários e nas gramáticas, e que, por isso, ignora os usuários reais e seus usos reais.

Outra das correntes que historicamente constituiu um terreno fértil no campo das pesquisas linguísticas no Brasil é a denominada Inatismo, cujo maior expoente é Chomsky. A base filosófica desta perspectiva é o logicismo. Os alicerces desta corrente defendem uma reflexão em que a atividade mental é o meio para o desenvolvimento humano. $\mathrm{O}$ foco aqui é a mente do ser que fala/escreve a língua, como a gênese de seu próprio uso. $\mathrm{O}$ uso da língua é individual, fruto da consciência de um indivíduo. Como se pode perceber, a noção de língua é ideal, como uma entidade do espírito ou da alma do indivíduo. Tudo que é exterior à mente desse indivíduo serve apenas para ser usado como objeto do pensamento, e ganha existência somente nessa relação com a mente do ser pensante. Nada que ocorra em 
uma situação concreta, externa ao indivíduo, pode alterar a pureza da realização de sua mente. Sobre isso, Bakhtin (2010) ensina que

o subjetivismo individualista apoia-se também sobre a enunciação monológica como ponto de partida da sua reflexão sobre a língua. É verdade que seus representantes não abordaram a enunciação monológica do ponto de vista do filólogo de compreensão passiva, mas sim de dentro, do ponto de vista da pessoa que fala, exprimindo-se. (BAKHTIN, 2010, p. 114)

Para Borges Neto (2004), enquanto no Estruturalismo o linguista descreve a língua a partir de um corpus de significado representativo para o estudo que era descrito pelo método da descoberta, de acordo com esse autor, ao tratar do Inatismo, para Chomsky o que chama a atenção

é a necessidade de se supor a existência de algo anterior à língua dos estruturalistas: a capacidade que os falantes têm de produzir exatamente os enunciados que podem ser feitos [...] desloca a questão fundamental da teoria linguística para a determinação das regras que regem os "corpora representativos", que deixam assim de ser o ponto de partida da teoria linguística e passam a ser o seu ponto de chegada. (BORGES NETO, 2004, p. 99. Grifos do autor)

Todavia, assim como o Estruturalismo, o Inatismo chomskiano também recebe considerações críticas de vários lados. A principal acusação é a mesma que o estruturalismo recebe: desconsiderar a interação social e os aspectos culturais da linguagem, se aprisionando ao ato monológico. A contundência maior dessa denúncia vem de Bakhtin (2010), ao escrever que "[a] palavra dirige-se a um interlocutor: ela é função da pessoa desse interlocutor: variará se se tratar de uma pessoa do mesmo grupo social ou não, se esta for inferior ou superior na hierarquia social, se estiver ligada ao locutor por laços sociais mais ou menos estreitos" (BAKHTIN, 2010, p. 116). O mesmo autor alerta ainda que a estrutura da enunciação é determinada completamente pelas situações sociais, imediatas e amplas, pois na visão dele "a situação dá forma à enunciação" e suplanta de vez a tese inatista ao defender que "sem uma orientação social de caráter apreciativo não há atividade mental" (BAKHTIN, 2010, p. 118 e 119). Como se pode perceber após essas contribuições do autor russo expressas neste texto, nem a linguística do sistema, tampouco a visão mentalista podem dar conta do que é a essência da língua, qual seja, na opinião dele, a interação. Nas palavras do próprio Bakhtin (2010):

[a] verdadeira substância da língua não é constituída por um sistema abstrato de formas linguísticas nem pela enunciação monológica isolada, nem pelo ato psicofisiológico de sua produção, mas pelo fenômeno social da interação verbal, 
realizada através da enunciação ou das enunciações. A interação verbal constitui assim a realidade fundamental da língua. (BAKHTIN, 2010, p. 127. Grifos do autor)

Quem também tece críticas ao Inatismo são os estudiosos Pêcheux e Gadet (1998), para os quais "a gramática gerativa não tem nada a dizer sobre a relação entre língua e formação social" (PÊCHEUX; GADET, 1998, p. 02. Grifos do autor). Conforme Oliveira (2004) os gerativistas entendem a sintaxe como se fosse autônoma, uma máquina de gerar sentenças, todas bem formadas, sem levar em conta a semântica, a pragmática; anterior aos usos. Essa autora ensina ainda que a tese do gerativismo é a de uma autonomia pura, e acrescenta:

[é] nessa direção que se deve compreender a afirmação de Chomsky de que a linguagem surgiu na espécie humana por um acaso. É assim que ela foi sempre sintaxe. Não há, pois, uma história de autonomia. Nessa perspectiva, a linguagem não é uma consequência da comunicação, não é um sistema de comunicação sofisticado; antes, ela surge de uma mutação genética que permitiu ao indivíduo a possibilidade de organizar melhor sua vida mental, tornando-o mais apto. Que a linguagem sirva a comunicação é uma consequência inesperada de termos linguagem, mas não essencial. (OLIVEIRA, 2004, p. 225 e 226)

Em virtude dessa ampla gama de críticas à linguística do sistema e à linguística mentalista, muitos estudiosos/pesquisadores passaram a encampar uma visão de linguagem e de língua que tem sua essência na interação social. Essa corrente do pensamento, denominada Interacionismo, é outra das mais férteis no Brasil, mais acentuadamente nas últimas décadas do século passado e neste século atual. A base teórica dessa visão vem, sobretudo, dos russos Bakhtin e Vygotsky, adeptos do Materialismo Histórico-Dialético. Como argumenta Morato (2004), o advento do interacionismo marca uma reação teórica externalista frente às correntes psicologistas, internalistas. De acordo com essa autora

podem ser considerados interacionistas aqueles domínios da Linguística - como a Sociolinguística, a Pragmática, a Psicolinguística, a Semântica Enunciativa, a Análise da Conversação, a Linguística Textual, a Análise do Discurso que se pautam por uma posição externalista a respeito da linguagem [...] pelo modo através do qual ela se relaciona com seus exteriores teóricos, com o mundo externo, com as condições múltiplas e heterogêneas de sua constituição e funcionamento. (MORATO, 2004, p. 311 e 312)

A linguística interacional tende a levar em consideração as manifestações da linguagem nas dinâmicas históricas, sociais e culturais, ao 
contrário da noção estrutural e da visão que entende a linguagem como expressão mental. Desta feita, as trocas entre os usuários marcam a essência da língua, partindo das condições materiais de uso. Os significados e os sentidos são frutos dessas trocas situadas, marcados pelo contexto de uso, pelas condições de sua produção, determinados ideologicamente. A respeito disso, Bakhtin (2010) explica que o usuário da língua se serve dela para suas necessidades concretas, pois o significado da forma está em um contexto concreto e que isso faz de um símbolo um signo. Do prisma bakhitiniano, "se concedermos um estatuto separado à forma vazia de ideologia, só encontraremos sinais e não mais signos de linguagem", pois conforme sua visão, a língua, "no seu uso prático, é inseparável de seu conteúdo ideológico ou relativo à vida" (BAKHTIN, 2010, p. 99). Na concepção de interação trazida por esse autor, uma enunciação só é percebida em sua completude quando relacionada a outras enunciações com as quais participa em um "único e mesmo domínio ideológico" (BAKHTIN, 2010, p. 108). Para ele, uma palavra é o produto tanto do locutor quanto do ouvinte, na interação entre os dois, ambos a compreendem dentro de limites sociais concretos; assim, o núcleo organizador de "toda enunciação, de toda expressão, não é interior, mas exterior: está situado no meio social que envolve o indivíduo" [...], na medida em que a "palavra é ideológica e toda utilização da língua está ligada à evolução ideológica" (BAKHTIN, 2010, p. 125 e 126). Nesse sentido, para não deixar dúvidas acerca de sua tese, bem como de onde advêm seus fundamentos, o estudioso russo propõe que

[u]ma análise fecunda das formas do conjunto de enunciações como unidades reais na cadeia verbal só é possível de uma perspectiva que encare a enunciação individual como um fenômeno puramente sociológico. A filosofia marxista da linguagem deve justamente colocar como base de sua doutrina a enunciação como realidade da linguagem e como estrutura sócio-ideológica. (BAKHTIN, 2010, p. 131)

Toda essa forma de compreender a língua levou à escola uma exigência de mudar seu objeto para as aulas de português, uma nova postura para o professor frente aos alunos e suas vozes, bem como encaminhou à escola o desenvolvimento de diversas pesquisas para investigar as mudanças ou implementar o novo objeto: os diversos gêneros textuais, entendidos como os marcadores do papel sociocultural da interação entre os interlocutores, materializadores da essência da língua; para levar a língua real para dentro dos muros da escola, para fazer dos aprendizes sujeitos de sua interação, inclusive desempenhando papeis de autores de textos verdadeiramente comunicativos, orais e escritos. A respeito dessa proposta, segundo Travaglia (2003), é preciso "propiciar o contato do aluno com a maior variedade possível de situações de interação comunicativa por meio de um trabalho de análise e produção de enunciados ligados aos vários tipos 
de situações de enunciação" (TRAVAGLIA, 2003, p. 18). Na mesma linha de raciocínio, Antunes (2004) propõe que a escrita seja entendida como uma "modalidade da língua", que existe para "cumprir diferentes funções comunicativas... para toda a comunidade" (ANTUNES, 2004, p. 47). Possenti (2003) também encampa essa visão de que a escola deve abrir-se à pluralidade dos discursos sociais, fazendo uso do texto como mediação comunicativa para tal feito. Koch (2002) também corrobora essa visão, ensinando que "[a] função textual diz respeito à criação de textos de modo pertinente ao contexto" e acrescenta ainda que "ao professor cabe a tarefa de despertar no educando uma atitude crítica diante da realidade em que se encontra inserido" (KOCH, 2002, p. 20 e 159). Em acréscimo a essa crítica aos modelos tradicionais, a ideia é a promoção de outros conteúdos a serem ministrados, de outros objetivos a serem alcançados, de novos métodos a serem aplicados, para que surja uma educação linguística que transforme a vida das pessoas, como disse Marcuschi (2008), "um convite claro para o ensino situado em contextos reais da vida cotidiana." (MARCUSCHI, 2008, p. 173).

\section{A Análise do Discurso em Michel Foucault: por uma linguística do enunciado}

A descrição do acontecimento do discurso coloca uma outra questão bem diferente: como apareceu um determinado enunciado, e não outro em seu lugar? (FOUCAULT, 2010)

Após tecer essas noções teóricas e visões que situam os campos da pesquisa em linguística e de práticas escolares com a Língua Portuguesa na escola, é possível retomar a questão proposta neste texto: por que uma linguística do Enunciado? Para tentar respondê-la será necessário trazer a contribuição e a visão de alguns estudiosos da Análise do Discurso, principalmente a posição de Michel Foucault acerca dos posicionamentos dessas correntes trazidas até aqui, bem como a exposição teórica e filosófica desse estudioso no que tange aos interesses deste texto.

Em princípio, é importante dizer que, para a $\mathrm{AD}$, a língua não é apenas em uma estrutura, ou em um sistema mental universal, ou na troca de informações, tampouco em uma comunicação contextual ideologicamente determinada. Por isso, não se encontrará na $\mathrm{AD}$ uma noção estática da língua, nem a ideia de um sujeito detentor do sentido de tudo que diz, tampouco uma visão de sociedade homogênea, com o dom da comunicação transparente. Para a AD, então, a língua é opaca; o sujeito é sempre colocado em check em seu inconsciente e em seus relacionamentos com os seus interlocutores. Assim, o que existe é o discurso, ou mais que isso, o que existem são formações discursivas historicamente constituídas, efeitos de sentido distintos em cada formação discursiva diferente. Por esse razão, nos estudos linguísticos, de acordo com o filósofo Michel Foucault (2010), o que deve ser analisado é o discurso e no discurso o foco 
não é o sistema de sua língua, nem, de uma maneira geral, as regras formais de sua construção; [...] A questão que coloco é aquela, não dos códigos, mas dos acontecimentos: a lei da existência dos enunciados, o que os torna possíveis - eles e algum outro em seu lugar; as condições de sua emergência singular, sua correlação com outros acontecimentos anteriores ou simultâneos, discursivos ou não. [...] sem me referir à consciência, obscura ou explícita, dos sujeitos falantes; sem relacionar os fatos de discurso à vontade - talvez involuntária de seus autores; sem invocar essa intenção de dizer que é sempre com excesso de riqueza em relação ao que diz; [...] nem uma formalização nem uma exegese. Mas uma arqueologia: quer dizer, como seu nome indica de maneira bastante evidente, a descrição do arquivo. (FOUCAULT, 2010, p. 09)

Dessa maneira, o filósofo francês rechaça as ideias do estruturalismo saussuriano, do gerativismo chomskiano e do interacionismo bakhitiniano. Ao trazer sua posição Foucault não apenas apresenta as falhas vistas por ele nessas formas de compreensão filosóficas e teóricas, mas também estabelece um pouco do perímetro de seu trabalho para suprir essas falhas; a saber, a noção de Arqueologia, as noções de discurso, de formações discursivas, de enunciado, de acontecimento, de sujeito, de condições de produção, de efeitos de sentido, de memória discursiva, de arquivo.

Não é o interesse deste texto dissecar todos esses conceitos, mas relacioná-los à busca pela resposta à questão levantada para este trabalho. $\mathrm{O}$ que pode ser destacado é que Foucault substitui os princípios teóricos das referidas linhas de pensamento por outros princípios aos quais ele considera mais abrangentes e mais pertinentes aos seus intuitos investigativos: em vez de limitar-se ao sistema da estrutura, ao conteúdo de uma mente superior, à ideologia de sujeitos contextualizados e dotados de uma consciência inequívoca de sua interação; expande a sua análise para o sistema do acontecimento, para a emergência sempre presente do enunciado, para o discurso e suas cadeias, para a rede dos enunciados. No lugar do a priori formal, ou do a priori mental, ou do a priori contextual para a comunicação, ele problematiza as regras do enunciado constituídas, as regras em construção, integradas em um a priori histórico. Como esclarece o próprio Foucault (2000):

[a] história que não é estrutura, mas vir a ser; que não é simultaneidade, mas sucessão; que não é sistema, mas prática; que não é forma, mas esforço incessante de uma consciência retomando a si mesma e tentando se ressarcir até o mais profundo de suas condições." (FOUCAULT, 2000, p. 86)

Para o citado filósofo, é preciso se libertar das noções de continuidade; de tradição; de influência; de desenvolvimento; de mentalidade ou espírito de uma época; "abandonar essas sínteses fabricadas, 
esses agrupamentos que são aceitos antes de qualquer exame, essas ligações cuja validade é admitida de saída;" assim como deixar de lado a ligação dos pensamentos dos homens aos seus discursos, não aceitar mais os recortes, nem "a distinção dos grandes tipos de discurso", das "formas ou gêneros" (FOUCAULT, 2000, p. 88). É preciso abandonar a "história das ideias", recusar "seus postulados" e "seus procedimentos" (FOUCAULT, 2010, p. 169). Conforme explica Foucault, ao abandonar essas noções tidas previamente, tem-se liberado para estudo um domínio que é constituído por um conjunto de enunciados efetivos e, por isso, cabe perguntar como surge "um determinado enunciado e não outro em seu lugar" (FOUCAULT, 2010 p. 33). O foco para a análise estará na ordem do acontecimento, para o fato de discurso que deve ser compreendido "em sua irrupção histórica; [...] essa incisão que o constitui, essa irredutível [...] emergência" (FOUCAULT, 2000, p. 93). Um acontecimento enunciativo se articula com outros sistemas de acontecimentos que lhe são exteriores, de ordens diversas e distintas. Como visto em Foucault (2010), "por certo: inicialmente porque está ligado, de um lado, a um gesto de escrita ou à articulação de uma palavra, mas, por outro lado, abre para si mesmo uma existência remanescente no campo de uma memória, ou na materialidade" (FOUCAULT, 2010, p. 35 e 36). O mesmo filósofo ensina ainda que o enunciado é único, porém está "aberto à repetição, à transformação, à reativação" por se ligar a outros enunciados que o antecedem e a outros mais que o sucedem (FOUCAULT, 2010, p. 36). Nessa medida, Foucault (2000) apresenta a base de sua arqueologia:

[o] que se trata de fazer aparecer é o conjunto de condições que regem, em um momento dado e em uma sociedade determinada, o surgimento dos enunciados, sua conservação, os laços estabelecidos entre eles, a maneira pela qual os agrupamentos em conjuntos estatutários, o papel que eles exercem, a série de valores ou de sacralizações pelos quais são afetados, a maneira pela qual são investidos nas práticas ou nas condutas, os princípios segundo os quais eles circulam, são recalcados, esquecidos, destruídos ou reativados. [...] tratar-seia do discurso no sistema de sua institucionalização. Chamarei de arquivo [...] o jogo das regras que, em uma cultura, determinam o aparecimento e o desaparecimento de enunciados, sua permanência e seu apagamento, sua existência paradoxal de acontecimentos e de coisas. [...] considerá-los não absolutamente como documentos [...] mas como monumentos; [...] como uma arqueologia. (FOUCAULT, 2000, p. 95. Grifos do autor)

Com base nessa citação pode-se afirmar que, para Foucault, o estudo da linguagem deve buscar a exterioridade que está além da língua e da consciência, para problematizar, o que supera a imposição ideológica e a determinação contextual: o sistema exterior que reside no campo dos acontecimentos; importa descrever os discursos e suas práticas que dão 
condição de surgimento e perpetuação aos enunciados, que marcam sua existência e sua rede de coexistência. Como o próprio autor salienta, seu objeto é

o arquivo, ou seja, a existência acumulada dos discursos [...] não somente da língua que permite dizer, mas dos discursos que foram ditos $[. .$.$] os discursos se encadeiam sob a forma de$ história [...] mas desde que se trate de determinar o sistema de discurso no qual ainda vivemos, no momento em que somos obrigados a questionar palavras que ressoam ainda em nossos ouvidos. (FOUCAULT, 2000, p. 72, 73,75 e 76)

É fundamental ressaltar que não interessa a esse filósofo saber quem foi a primeiro a dizer ou quem será a última fonte do discurso. Foucault (2000) se interessa antes pelas superfícies óbvias ou visíveis do discursivo, o que está presente no próprio discurso, tomando-o na consistência de suas práticas e regras de sua formação, sua materialidade constituinte, sua existência que se tem manifesta. Ao fazer isso o citado filósofo também põe em check o estatuto de sujeito origem, aquele que é capaz de usar a língua a seu serviço e intencionalidade. $\mathrm{O}$ fato de existir o enunciado depende de uma série de fatores que determinam que seja de uma pessoa e não de outra pessoa a voz que soa no discurso, que seja de uma pessoa e não de outra pessoa a escrita que grafa o texto. Nas palavras de Foucault (2010), "[n]ão é preciso remeter o discurso à longínqua presença da origem; é preciso tratálo no jogo de sua instância" (FOUCAULT, 2010, p. 31). O mesmo pensador acentua que

todo discurso manifesto repousaria secretamente sobre um jádito; e que este já-dito não seria simplesmente uma frase já pronunciada, um texto já escrito, mas um "jamais-dito", um discurso sem corpo, uma voz tão silenciosa quanto um sopro, uma escrita que não é senão o vazio de seu próprio rastro (FOUCAULT, 2010, p. 30. Grifos do autor).

Se há regras para analisar, na opinião de Foucault (2010), devem ser focadas as regras de formação dos objetos discursivos, de suas operações, de sua conceituação e de suas opções teóricas, para fazer proliferar os sistemas, os feixes de relações que se estabelecem nos discursos. No interior dessa discussão, Dosse (2007) encampa essa visão e se dedica a explicar que o "enunciado é uma verdadeira coisa situada num entremeio, com a língua como sistema de regras de um lado e, do outro, o corpus como discurso efetivamente pronunciado" (DOSSE, 2007, p. 301). O mesmo autor acrescenta que um enunciado não se fecha sobre si mesmo, mas ao contrário, está em relação com outros enunciados. Vale trazer aqui a explicação mais direta e explícita de Foucault (2010): 
[e]is a questão que a análise da língua coloca a propósito de qualquer fato de discurso: segundo que regras um enunciado foi construído e, consequentemente, segundo que regras outros enunciados semelhantes poderiam ser construídos? A descrição de acontecimentos do discurso coloca uma outra questão bem diferente: como apareceu um determinado enunciado, e não outro em seu lugar? (FOUCAULT, 2010, p. 33)

O grau de dificuldade em seguir nessa direção apontada por Foucault reside na tradição insistente de querer dar uma resposta final para todas as pesquisas, esquadrinhar, estabilizar; quase sempre buscando uma resposta acertada ao que se propõe. Essa herança positivista, atomística; a persistente presença do sistema saussuriano; a sempre forte dimensão da lógica idealista; a emergência cada vez mais acentuada das noções funcionalista e interacionista; a marca constante do empirismo; a permanência do logicismo e a forte filosofia materialista histórico-dialética são fatores que podem propiciar o estranhamento por parte de alguns estudiosos em relação ao que propõe Foucault. Como o próprio filósofo ensina, o perigo reside em sermos "obrigados a continuar fora das paisagens familiares, longe das garantias a que estamos habituados, em um terreno ainda não esquadrinhado e na direção de um final que não é fácil prever" (FOUCAULT, 2010, p. 48).

Foucault (2010) reitera que o enunciado não se esconde, não está na escuridão interpretativa para que possa ser uma coisa ou outra, mas também não é limitado aos caracteres da língua, "o nível enunciativo está no limite da linguagem" (FOUCAULT, 2010, p.137). O citado filósofo prossegue: "[e]nquanto uma enunciação pode ser recomeçada ou reevocada, enquanto uma forma (linguística ou lógica) pode ser reatualizada, o enunciado tem a particularidade de poder ser repetido: mas sempre em condições estritas" (FOUCAULT, 2010, p.128. Grifos do autor). Isso ocorre marcadamente pelo fato de um enunciado se inserir em um campo de utilização, numa forma que pode ser indefinidamente repetível apesar de sua materialidade característica; ele se encontra em um jogo, em meio a outros enunciados, uma vez que "não há enunciado que, de uma forma ou de outra, não reatualize outros enunciados" (FOUCAULT, 2010, p. 119).

É importante também ressaltar aqui as implicações que o trabalho de Michel Foucault pode trazer às situações práticas de ensino da língua na escola. A elevação da análise do nível da estrutura para a ordem do discurso, na rede de enunciados, na emergência dos acontecimentos, em primeira instância, apaga a possibilidade de o estudante não perceber a relação língua-sociedade. Noutra direção, impossibilita que a relação do estudante com a língua seja de uma maneira apenas lógica, maneira característica do preconceito que denuncia os maus alunos (aqueles que pensam e agem fora da forma delimitada) e separa os bons (os outros que cumprem à risca a reprodução das formas do pensamento e das ações determinadas pelo professor). Finalmente, a aula de língua deve extrapolar a análise 
funcionalista das frases e dos textos situados no contexto, com determinações ideológicas definidas, bem como uma semântica das enunciações que são produzidas pelos sujeitos e recepcionadas pelos interlocutores, numa espécie de acordo interativo que é imperado pela determinação de onde e com quem se fala, a respeito de um conteúdo compartilhado. Assim, a perspectiva de trabalho que se abre a partir da filosofia foucaultiana caminha para a historicidade dos acontecimentos, para a materialidade dos enunciados, das formações discursivas que se entrelaçam na emergência e na dispersão desses acontecimentos enunciativos. Como disse Foucault (2010):

substituir o tesouro enigmático das "coisas" anteriores ao discurso pela formação regular dos objetos que só nele se delineiam; [...] relacionando-os ao conjunto de regras que permitem formá-los como objetos de um discurso e que constituem, assim, suas condições de aparecimento histórico; [...] elidir o momento das "próprias coisas" não é remeter necessariamente à análise linguística da significação [...] tratase de identificar os relacionamentos que caracterizam uma prática discursiva e não se determina uma organização léxica nem as escansões de um campo semântico. (FOUCAULT, 2010, p. 58. Grifos do autor)

O filósofo reforça ainda mais sua defesa ao afirmar que sem enunciados não há existência da língua, pois o sistema da língua só existe para a construção de enunciados possíveis. No esclarecimento de Foucault (2010), o enunciado nunca deverá ser confundido com agrupamento de signos, uma vez que ele

não é nem sintagma, nem regra de construção, nem forma canônica de sucessão e de permutação, mas sim o que faz com que existam tais conjuntos de signos e permite que essas regras e essas formas se atualizem [...] não se poderia confundir com a existência dos signos enquanto elementos de uma língua [...] uma série de signos se tornará enunciado com a condição de que tenha com outra coisa [...] uma relação específica que se refira a ela mesma - e não à sua causa, nem a seus elementos. (FOUCAULT, 2010, p. 106 e 107. Grifos do autor)

Apenas a título de exemplo prático, vale pensar o quanto seria mais interessante para a formação do estudante se esse estudante pudesse se dedicar à análise dos acontecimentos enunciativos, dos discursos que povoam sua contemporaneidade; tais como os ouvidos e os lidos durante as últimas manifestações sociais que tomaram as ruas das grandes cidades do Brasil; ou os expressos na televisão, no rádio, em revistas esportivas e jornais esportivos impressos a respeito do jogador que se responsabilizará pela mística da camisa 10 da seleção brasileira; ou os discursos trazidos à população pelas mídias em relação à "Operação Lava-Jato"; aos 
acontecimentos políticos que cercam a CPI da Petrobras. Apresentado à historicidade desses discursos, às formações discursivas a que pertencem esses discursos, estaria esse estudante sendo impulsionado a pensar a respeito do por que esses discursos aparecem e não outros em seu lugar; a refletir porque alguém e não outro alguém estaria autorizado a dizer o que diz, a escrever o que escreve. Dessa perspectiva, "a descrição histórica das coisas ditas é inteiramente atravessada pela oposição do interior e do exterior" e estabelecer "a história do que foi dito é refazer, em outro sentido, o trabalho da expressão" (FOUCAULT, 2010, p. 148). Por ser assim, entraria para o corpus do estudo não apenas a estrutura gramatical, a lógica do dito enquanto pensamento de um sujeito intencional, o que se poderia interpretar a partir da enunciação, mas a exterioridade, o arquivo ao qual integram esses discursos, sua raridade, seus aspectos de remanência, as práticas que permitem estabelecer sua emergência enquanto acontecimento enunciativo; pois como sustenta Foucault (2010) "o que importa é reencontrar o exterior onde se repartem, em sua relativa raridade, em sua vizinhança lacunar, em seu espaço aberto, os acontecimentos enunciativos" (FOUCAULT, 2010, p. 149). Nessa empreitada, o mesmo filósofo encampa a ideia de que faz-se necessária a substituição das análises das totalidades pela raridade, do fundamento transcendental pela exterioridade, da busca pela origem por uma análise dos acúmulos e, assim, "revelar, com o arquivo, as formações discursivas, as positividades, os enunciados e suas condições de formação, um domínio específico que não constitui, ainda, objeto de nenhuma análise." (FOUCAULT, 2010, p. 250) 


\section{Referências bibliográficas}

ANTUNES, Irandé. Aula de português: encontro \& interação. 2. ed. São Paulo: Parábola, 2004.

BAKHTIN, Mikhail. Marxismo e Filosofia da Linguagem. 14ª. ed. São Paulo: Hucitec, 2010.

BORGES NETO, José. O Empreendimento Gerativo. In: MUSSALIM, Fernanda; BENTES, Anna Christina (Org.) Introdução à linguística: fundamentos epistemológicos. São Paulo: Cortez, 2004. V.3 (p. 93 - 129)

DOSSE, François. História do estruturalismo. Bauru, SP: Edusc, 2007. V.2 (O canto do cisne)

FOUCAULT, Michel. Michel Foucault explica seu último livro. In: FOUCAULT, Michel. Arqueologia das ciências e história dos sistemas de pensamento. (Col. Ditos e escritos, II). Rio de Janeiro: Forense Universitária, 2000. (p. 145-152).

. Sobre as maneiras de escrever a História. In: FOUCAULT, Michel. Arqueologia das ciências e história dos sistemas de pensamento. (Col. Ditos e escritos, II). Rio de Janeiro: Forense Universitária, 2000. (p. 62-77).

- Sobre a arqueologia das ciências. Resposta ao círculo de epistemologia. In: FOUCAULT, Michel. Arqueologia das ciências $e$ história dos sistemas de pensamento. (Col. Ditos e escritos, II). Rio de Janeiro: Forense Universitária, 2000. (p. 82-118).

Linguística e Ciências Sociais. In: FOUCAULT, Michel. Arqueologia das ciências e história dos sistemas de pensamento. (Col. Ditos e escritos, II). Rio de Janeiro: Forense Universitária, 2000. (p. 40-55).

Retornar à história. In: FOUCAULT, Michel. Arqueologia das ciências e história dos sistemas de pensamento. (Col. Ditos e escritos, II). Rio de Janeiro: Forense Universitária, 2000. (p. 260-281).

Introdução (in: Arnauld e Lancelot). In: FOUCAULT, Michel. Arqueologia das ciências e história dos sistemas de pensamento. (Col. Ditos e escritos, II). Rio de Janeiro: Forense Universitária, 2000. (p. 119-140).

Resposta a uma questão. In: FOUCAULT, Michel. Repensar a política. (Col. Ditos e escritos, VI). Rio de Janeiro: Forense Universitária, 2010. (p. 1-24).

A arqueologia do saber. 8. ed. Rio de Janeiro: Forense Universitária, 2012.

GERALDI, João. Wanderley. Portos de passagem. 4. ed. São Paulo: Martins Fontes, 2002.

KOCH, Ingedore Villaça. Argumentação e linguagem. 7. ed. rev. São Paulo: Cortez, 2002.

MARCUSCHI, Luiz Antônio. Produção textual, análise de gêneros $e$ compreensão. São Paulo: Parábola, 2008.

MORATO, Edwiges Maria. O interacionismo no campo linguístico. In: MUSSALIM, Fernanda; BENTES, Anna Christina (Org.) Introdução à

A análise arqueológica do discurso em Michel Foucault: por uma linguística do enunciado - Sérgio Gomes de Miranda 
linguística: fundamentos epistemológicos. São Paulo: Cortez, 2004. V.3 (p. $311-352)$

OLIVEIRA, Roberta Pires de. Formalismos na linguística: uma reflexão crítica. In: MUSSALIM, Fernanda; BENTES, Anna Christina (Org.) Introdução à linguística: fundamentos epistemológicos. São Paulo: Cortez, 2004. V.3 (p. 219 - 250)

PÊCHEUX, Michel; GADET, Françoise. Há uma via para a linguística fora do logicismo e do sociologismo? In: Escritos. Unicamp: Labeurb, n. 3, 1998.

POSSENTI, Sírio. Por que (não) ensinar gramática na escola. Campinas: Mercado das Letras, 1996.

TRAVAGLIA, Luiz Carlos. Gramática e interação: uma proposta para o ensino de gramática. 9. ed. rev. São Paulo: Cortez, 2003. 